TI 2011-104/3

Tinbergen Institute Discussion Paper

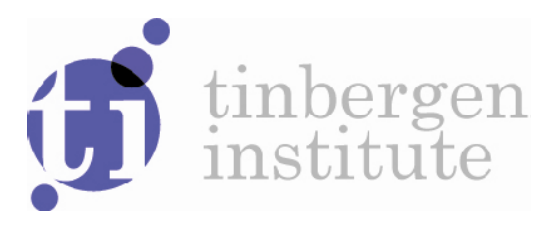

\title{
Regional Labour Markets and Job Accessibility in City Network Systems in Germany
}

Aura Reggiani*

Pietro Bucci"**

Giovanni Russo****

Anette Haas *****

Peter Nijkamp****

* University of Bologna, Italy;

** Significance, The Hague, The Netherlands;

*** VU University Amsterdam; The Netherlands;

$*^{*} \cdots *$ Institute for Employment Research, Nürnberg, The Netherlands. 
Tinbergen Institute is the graduate school and research institute in economics of Erasmus University Rotterdam, the University of Amsterdam and VU University Amsterdam.

More TI discussion papers can be downloaded at http://www.tinbergen.nl

Tinbergen Institute has two locations:

Tinbergen Institute Amsterdam

Gustav Mahlerplein 117

1082 MS Amsterdam

The Netherlands

Tel.: +31(0)205251600

Tinbergen Institute Rotterdam

Burg. Oudlaan 50

3062 PA Rotterdam

The Netherlands

Tel.: +31(0)10 4088900

Fax: +31(0)104089031

Duisenberg school of finance is a collaboration of the Dutch financial sector and universities, with the ambition to support innovative research and offer top quality academic education in core areas of finance.

DSF research papers can be downloaded at: http://www.dsf.nl/

Duisenberg school of finance

Gustav Mahlerplein 117

1082 MS Amsterdam

The Netherlands

Tel.: +31(0)20 5258579 


\title{
REGIONAL LABOUR MARKETS AND JOB ACCESSIBILITY IN CITY NETWORK SYSTEMS IN GERMANY
}

\author{
Aura Reggiani*, Pietro Bucci**, Giovanni Russo***, Anette Haas****, Peter \\ Nijkamp***
}

* University of Bologna, Department of Economics, Piazza Scaravilli, 2, 40126 Bologna, Italy; email: aura.reggiani@unibo.it

** Significance, Koninginnegracht 23, 2514 AB The Hague, The Netherlands; email: bucci@significance.nl

*** VU University, Amsterdam, Department of Spatial Economics, The Netherlands; email: grusso@feweb.vu.nl; pnijkamp@feweb.vu.nl

***** Institute for Employment Research, Regensburger Strasse 104, 90478 Nürnberg, Germany, email: anette.haas@iab.de

\begin{abstract}
Spatial labour markets are subjected to the forces of regional economic activity and competing network effects. Commuting is, therefore, an important equilibrating vehicle in a city network constellation. Cities act as attractors of commuters, as most economic activity occurs in cities, thus providing a high share of attractive workplaces. Cities that are centrally connected in a network may act as both centripetal and centrifugal forces in the whole system. The present paper focuses on what is named the City Network (CN) approach. A central idea is the accessibility concept, which is interpreted here as the potential of opportunity for interaction, which has a positive impact on economic growth. In our paper, the accessibility concept and the $\mathrm{CN}$ concept are linked together by positioning accessibility in the CN system. Since accessibility measures give geographical insights into the distribution of economic activities and the related (dis)equilibrium of regional development patterns, the connection with the labour market is evident, and, therefore, a second focus of our analysis.

In an applied setting, our paper aims to investigate spatial accessibility patterns in the main $\mathrm{CN}$ in Germany. The 17 districts which belong to the country's CN were chosen from the 439 German labour market districts on the basis of three criteria: (a) their connection to the high speed railway network; (b) the most accessible districts according to previous results (2002); (c) relevant districts for the German economy. Our applied modelling research concerns home-to-work commuters travelling between the selected districts belonging to the German CN, for both 2003 and 2007. Here, a comparative analysis of the ranking of the most accessible districts - also for different intra-zonal travel times - is carried out in order to map out the changes in accessibility between 2003 and 2007, especially in the light of new high speed connections and commuting flow dynamics.
\end{abstract}

Keywords: regional labour market, City Network, accessibility, commuting, German districts 


\section{Introduction}

The dispersion of economic activity has never shown a static picture, but has always been in a state of flux. Traditional location theory has argued that scale and agglomeration advantages are largely responsible for the spatial clustering observed in the space-economy. The blend of physical geography and competitive economic behaviour is the main explanation for the diversity in location patterns of economic activity, an observation also made in the New Economic Geography (see, e.g., Fujita et al., 1999, Fujita and Thisse, 2002, Davis and Weinstein, 1999, Nijkamp 2008). Agglomeration externalities appear to be a powerful vehicle for shaping the economic geography of our world, as was convincingly demonstrated in the MAR (Marshall-Arrow-Romer) conceptualisation of spatial externalities and knowledge spillovers (see, e.g., Glaeser et al., 1992; Henderson et al,, 1995; van Oort and McCann, 2009). This complex spatial force field of the location of economic activity has immediate consequences for the functioning of various local and regional markets, such as the labour and housing market. These are subjected to the dynamics in the locational patterns of private and public agents (see Nijkamp, 2009; Quigley, 1998).

In the present paper we focus our attention on the spatial-economic position - and dynamics - of regional labour markets. It should be noted that labour markets are not isolated markets that are only connected to local activity. They form a network of interconnected markets that influence each other (e.g. through commuting flows), and that may exhibit a high degree of fluctuations caused by developments in the local economy and by competing socio-economic forces elsewhere.

Proximity of job opportunities (or job accessibility) is of course an important determinant of the evolution of a network of labour markets. And, therefore, it is of critical importance to investigate more thoroughly the position of local/regional labour markets in a broader network constellation of interconnected (competitive and complementary) labour markets. Indeed, in the past few decades we have witnessed a rising interest in the relevance of network concepts in the regional science and geography literature. Networks ${ }^{1}$ may be conceived of as interactive complex systems of organized activity, with various centripetal and centrifugal roles assumed by the actors involved (which may lead to a nonlinear and dynamic activity constellation). From this perspective, we can understand the analytical interest in mapping out the structure and evolution of complex spatial networks in recent regional economic research (Reggiani and Nijkamp, 2009).

The theoretical underpinning of the network concept originates from the view of the economy as a complex system or web of links between individuals, firms and institutions, where links evolve

\footnotetext{
1 "Networks (literally: operations via nets) may be interpreted as an ordered connectivity structure for dynamic spatial communication and transportation which is characterized by the existence of main nodes which act as receivers or senders (push and pull centres and which are connected by means of corridors and edges" (Reggiani and Nijkamp, 2006, p. 2).
} 
through learning processes among the actors involved. Consequently, networking in a city system's context can be considered as 'intra-cooperation' between individuals, firms, institutions in the cities, as well as 'inter-urban cooperation' between actors, treating cities as economic actors. In this context, the economic value of a network is positively affected by two elements: a) the number of locations it serves (network effect); b) the number of its users (production scale effect) (Pompili, 2006). Networks thus provide a platform which might ensure greater benefits to users (network externalities) leading to spatial agglomeration, as is also argued in the New Economic Geography. The relationship between growth and space deserves, however, some more attention.

The spatial clustering of economic activities has often been observed in the scientific literature as a result of economies of density or network agglomerations advantages (Glaeser, 1998; Krugman, 1996). In this context, we may quote Russo et al. (2007, p. 791), who argue that: “... cities act as catalysts for entrepreneurial activity, because entrepreneurial activity does not take place in a vacuum. In fact, besides the proximity of other fellow entrepreneurs, entrepreneurs in the knowledge economy need a large array of complementary services such as: financial services, a highly educated workforce, sources of knowledge (universities and research centers), logistic services, etc. There is an avalanche of recent studies that confirm the above premises."

The central role of cities in the context of agglomeration and economic growth analysis has also been emphasized by - among others - Duranton (2000, pp. 291-292): “The city is not only the place where growth occurs, but also is the engine of growth itself”; by Nijkamp (2008, p. 4): “The relationship between business life and the city is often underrepresented in urban economics, but deserves full-scale attention"; and by Quigley (1998, p.137): "Large cities have been and will continue to be an important source of economic growth." Somewhat in contrast, Polèse (2005) argues that the socio-economic processes that explain economic growth operate primarily at the national/societal level and not at the city level. This author points to the difficulty of rigorously testing the relationship between agglomeration and economic growth: "Part of the problem stems from the difficulty of distinguishing factors that allow cities to capture a greater share of national economic growth from those that allow cities to add to national economic growth" (Polèse, 2005, p. 1429).

Starting from this debate which centres on the existence of dynamic agglomeration economies, this paper aims to explore the role of cities as interconnected sources of economic activity and growth, by considering them not as isolated nodes, but as central poles in a spatial-economic network. In this context, we will draw attention to the geographically interacting network of major cities (called the City Network ' $\mathrm{CN}$ ') which, for spatial-economic reasons, tend to capture innovation and knowledge production. The rationale behind this is that the production of 
innovation/knowledge tends to have regional/local roots rather than national ones (Karlsson et al., 2006). As a consequence, a strategic relationship between the national economic growth and spatial concentration of people/firms in large urban regions is plausible (see, again, Karlsson et al., 2006). In other words, we conceive of the $\mathrm{CN}$ as a 'simple', though integrated, way to comprehend the 'complexity' of economic growth in a national system. This means that due attention should be given to the geographical spillover effects of urban nodes in a complex spatial network.

Modelling the patterns of new activities and innovation diffusion has been a fashionable topic in the literature in recent decades, and dates back to the seminal work of Hägerstrand (1953), who highlighted the importance of geographical perspectives in spatial systems. Knowledge flows are related to mobility and the interaction of people, so that, in general, spatial proximity may be assumed to be instrumental in facilitating knowledge among actors (Dosi, 1998). In fact, cities - by localizing productive and innovative activities - shape the geographical space that surrounds them. The availability of employment opportunities and the presence of fellow entrepreneurs - both competitive and complementary - will determine the size and direction of commuting flows. To the extent that information and knowledge is embodied in people, these will serve as a proxy for the flow of knowledge. Following Karlsson et al. (2006), our paper aims to go beyond the use of spatial proximity, by investigating the use of operational accessibility measures. This can provide insight into the propensity of employees (with different residential locations) to travel, at given travel times, to different destinations inside and outside cities/regions. It should be noted that the travel time data reflects the network connectivity structure. In this vein, we will focus on the labour market (aggregate) outcome of the decisions of individuals, as shaped by their 'network' access to job opportunities.

The paper offers an empirical example of the usefulness of the $\mathrm{CN}$ approach by applying it to Germany. In a nutshell, we will focus on the main cities/regions - and the labour market areas that surround them - in Germany. In fact, we will select those cities that are particularly important in terms of centrality for commuter flows. In this context, we hypothesize that this 'physical' $\mathrm{CN}$ might also be relevant as a 'virtual' network, given the strong spatial interaction leading to other kinds of networks (e-business, etc.). To this end, we will focus on the role of accessibility in capturing the patterns of exchanges between labour market areas. This is an important relationship because exchanges of labour may bring about changes in knowledge commuting flows, which can be a source of economic growth. We show that the core of the $\mathrm{CN}$ in Germany - as identified by means of proximity and agglomeration effects - is able to capture and map out a significant part of the complex relationships between regions. 
This paper is structured as follows. After this introduction, Section 2 focuses on the methodology and rationale underlying this work, while Section 3 presents a descriptive analysis of the selected CN system in Germany. Section 4 deals with the empirical analysis and is first devoted to the implementation - in the $\mathrm{CN}$ - of conventional accessibility measures (embedding two different deterrence functions). Then, accessibility rankings of the $\mathrm{CN}$ districts for different travel times and two different years (2003 and 2007) are displayed and analysed, with particular reference to their relationship with labour market rankings. Network policy issues and of future research are discussed in Section 5.

\section{The Methodology Adopted}

A $\mathrm{CN}$ is an interactive constellation for the force field exerted by various interconnected heterogeneous cities. Analysis of the resulting flows in the network can be undertaken by statistical/econometric methods, by simulation experiments, by GIS modelling, or by the assessment of structural parameters that reflect the interconnectivity and accessibility in a network.

It should be noted that the $\mathrm{CN}$ concept is strictly connected to the concept of hierarchy in a complex system. Already in 1962, Simon argued: “... complexity frequently takes the form of hierarchy... Hierarchy, I shall argue, is one of the central structural schemes that the architect of complexity uses" (p. 468). In addition, Simon also stresses the relevance of the strength of interaction in order to identify hierarchies: "If we make a chart of social interaction, of who talks to whom, the clusters of dense interaction in the chart will identify a rather well-defined hierarchic structure. The groupings in this structure may be defined operationally by some measure of frequency of interaction in this sociometric matrix" (1962, p. 469).

Starting from the above considerations, this paper focuses on the following interrelated objectives:

- exploration of the relevance of the premise 'from complexity to simplicity', by investigating the $\mathrm{CN}$ architecture, i.e. the network of major cities which tend to capture the innovation/knowledge communication and the business dynamics (e.g. in terms of jobs);

- exploration of the question whether a simple 'variable', like accessibility, is able to shed light on the concept of spatial proximity in knowledge communication, due to its capability of embedding the behavioural components (at aggregate level) of economic agents.

In this paper, we explore in particular the role of the cities as engines of the dynamics of labour market areas. Here we presume that knowledge flows, which "are more effective in cities where 
communication between people is more extensive" (Glaeser et al., 1992, pp. 1126-1127), move more quickly in the $\mathrm{CN}$. In this context, we will conceive of accessibility as a suitable variable able to measure the intensity of these knowledge flows. As anticipated in Section 1, commuter flows will serve as a proxy for these knowledge flows.

Accessibility $A_{i}$ in location $i$ is considered here as the potential of opportunities for interaction, for example, with activities or suppliers (Weibull, 1980). $A_{i}$ then measures the propensity of economic actors to reach certain economic activities/destinations $D_{j}$ :

$$
A_{i}=\Sigma_{\mathrm{j}} D_{j} \mathrm{f}\left(\alpha, c_{i j}\right)
$$

Accessibility $A_{i}$ is then explained by the sum of the discounted economic activities (workplaces) $D_{j}$, by means of a generalized non-linear discounted factor $\mathrm{f}\left(\alpha, c_{i j}\right)$. This discounted factor is a function of the commuting travel times/costs $c_{i j}$, while the parameter $\alpha$ is a time-cost sensitivity parameter, also depending negatively on the wage rate (see Bode, 2006). In our empirical case we will investigate two different non-linear forms for the function $\mathrm{f}\left(\alpha, c_{i j}\right)$ : a negative exponential expression, and a negative power function. We will test the sensitivity of these two expressions for a given data set.

Our final step will then be:

- an exploration of the relationship between labour market size (measured by workplaces) and accessibility (for different functional forms $\mathrm{f}\left(\alpha, c_{i j}\right)$ ) in the $\left.\mathrm{CN}\right)$. As mentioned in Section 1, our case study focuses on the German socio-spatial setting of regional labour markets. In other words, a perfect matching in ordinal terms - for a German city - between these two variables means a good consistency between economic activities/workplaces and accessibility, which also means an efficient organisation of the spatial distribution of jobs. It is, of course, a particularly intriguing question to what extent flows in a $\mathrm{CN}$ system are affected by the dynamics in the external environment (e.g. the introduction of radically new infrastructures which affect accessibility conditions). This is further treated in Sections 3 and 4.

\section{The German City Network}

\subsection{Descriptive Analysis}

In reccent years, important new infrastructures have been built in Germany. As a result, improvements in the connectivity of the network and in its speed have led to changes in the spatial 
structure of the country. In particular, when relevant transport improvements (e.g. the high speed train connection Munich-Berlin) are realized, the cities will be served by a high speed train function as main connectors with the rest of the country. This backbone system, called the City Network $(\mathrm{CN})$, can be considered the engine of the German transport network.

From a labour market perspective, large cities represent thick markets allowing for a better average match between workers and jobs; a large market permits specialization of workers, and therefore tends to be more efficient when employees are concentrated in cities.

The selected CN in Germany covers a system of 17 German core cities (see Table 1 and Figure 1) that have been chosen from the 439 Germany districts, on the basis of the following criteria (for each district):

a) most accessible on the basis of previous results (Reggiani and Bucci, 2008);

b) connection to the high speed railway network;

c) relevant for the German economy, as 4 per cent of the nodes capture 22 per cent of the national GDP.

As expected, the selection criteria for the $\mathrm{CN}$ yield an uneven spatial distribution. Even if the German reunification began with the removal of the border between East and West Germany in Berlin in 1989, accessibility is, nevertheless, strongly influenced by this unique history. There are only two cities in the East (Dresden and Leipzig), besides the special case Berlin, which are part of the network. Further differences between East and West concerning the pattern of labour markets are evident.

Over the last decade, in the western part of Germany, new workplaces have emerged not only in the core cities, but also in the commuter belts around these core cities. However, in the eastern part of Germany the considerable job growth is more or less restricted to the city districts (Granato et al., 2009; Niebhur et al., 2009; Uhlig, 2006). Therefore, we included the catchment areas around each selected district in our analysis in order to account for the whole range of influences of labour markets.

In order to analytically define the catchment area, we considered each district as the centroid of a wider area gravitating towards it from the commuting viewpoint. In particular, we selected commuting flows within 60 minutes of the centroid according to the functional labour market delineation $^{2}$ by Eckey et al. (2006). The related catchment areas ${ }^{3}$ concerning the selected 17 German districts - for the year 2007 - are also depicted in Figure 1.

\footnotetext{
${ }^{2}$ For the delineation of German labour market areas, Eckey et al. (2006) apply commuting time from 45 min. up to 60 min. according to the gravity of an area. Due to the high pull factor of cities, we include all commuting flows up to 60 $\min$.
} 
Table 1. The 17 districts selected for the City Network approach in Germany

\begin{tabular}{|l|l|l|}
\hline Berlin & Bonn & Bremen \\
\hline Dortmund & Dresden & Düsseldorf \\
\hline Essen & Frankfurt & Hamburg \\
\hline Hannover & Karlsruhe & Köln (Cologne) \\
\hline Leipzig & Mannheim & München (Munich) \\
\hline Nürnberg (Nuremberg) & Stuttgart & \\
\hline
\end{tabular}

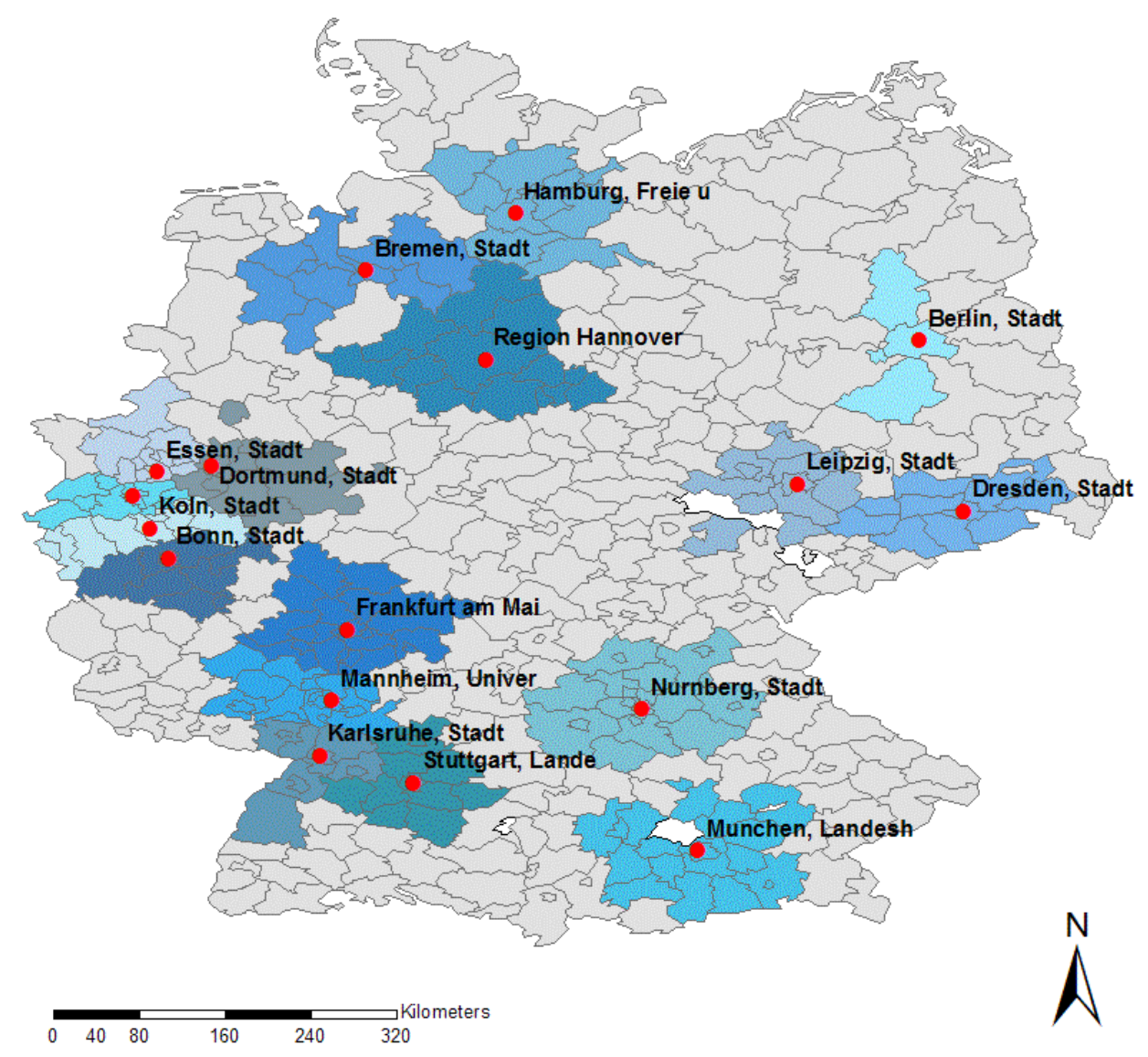

Figure 1. The catchment areas of the 17 districts belonging to the City Network (2007)

\footnotetext{
${ }^{3}$ In particular, the total number of districts - in relation to the catchment areas - is as follows: 214 (year 2003); 204 (year 2007).
} 
We can see in Figure 1 that there are overlapping labour market regions, e.g. the Rhine-Ruhr area which is the area with the highest population density. It is interesting to note that all these catchment areas account for about 67 per cent of the national GDP.

It should be noted that we will take into account - in the subsequent $\mathrm{CN}$ analysis - the catchment areas related to each district.

In the next section we provide some descriptive statistics - in terms of employment/commuting - of the $\mathrm{CN}$ vs. the whole Germany.

\subsection{Descriptive Statistics}

In this section, the development of the CN's employment/commuting pattern over the years (2003 and 2007) will be analysed. The descriptive statistics, presented in Tables 2- 4, provide information about the labour market in the CN (17 nodes), as well as in the whole of Germany (349 nodes). CN information also includes the related catchment areas.

The data are extracted from the employment history statistics of the IAB (Institute for Employment Research). The employment statistics cover all employees subject to social security contributions. Commuters are identified by comparison of place of work and place of residence in all districts. A commuter is defined as an employee who does not work in the same district where he/she lives. We excluded from our data set observations with missing values on place of work and place of residence.

It can be observed - in Table 2 - that the total employment for the whole Germany, decreased from $26,707,668$ (2003) to $26,666,895$ (2007). We consider only observations for which travel time was not missing ${ }^{4}$. The $\mathrm{CN}$ employment (including the internal flows of the 17 districts, as well as of their catchment areas) has decreased from 16,629,621 (2003) to 15,980,673 (2007), with a variation of -3.9 per cent.

It is interesting to note that the employment and GDP for the CN compared with the whole country are as follows:

- 2003: the CN's catchment areas account for 62 per cent of the total employment in Germany (Table 2), and for 69 per cent of the total GDP in Germany (Table 3);

- 2007: the CN's catchment areas account for 60 per cent of the total employment in Germany (Table 2) and for about 67 per cent of the total GDP ${ }^{5}$ in Germany (Table 3).

\footnotetext{
${ }^{4}$ For information, the overall total employment including those districts with missing travel time amounts to about 26,955,000 in 2003 and to about 26,855,000 in 2007.

${ }^{5}$ GDP data for the year 2007 were not available.
} 
Finally, Table 4 summarizes information on the $\mathrm{CN}$, indicating the ratio between the number of commuters and the total number of workers, which shows a slight increase from 26.5 per cent (2003) to 27.9 per cent (2007). This pattern shows stability within the CN. In addition, we can see in Table 4 that the commuting between the $\mathrm{CN}$ districts - excluding the internal flows - has increased from 4,408,220 (2003) to 4,464,101 (2007), with a variation of +1.3 per cent.

Table 2. Total employment in the CN and in the whole of Germany (2003 and 2007)

\begin{tabular}{cccc}
\hline \multirow{2}{*}{$\mathbf{2 0 0 3}$} & & Nodes & Total Employment \\
\cline { 2 - 4 } & CN & 17 & $16,629,621$ \\
\hline \multirow{2}{*}{2007} & Whole Germany & 439 & $26,707,668$ \\
\cline { 2 - 4 } & CN & 17 & $15,980,673$ \\
\cline { 2 - 4 } & Whole Germany & 439 & $26,666,895$ \\
\hline
\end{tabular}

Table 3. GDP (in mln euros) for CN including its catchment areas (2003 and 2007)

\begin{tabular}{lcc}
\hline GDP & $\mathbf{2 0 0 3}$ & $\mathbf{2 0 0 7}$ (GDP for 2006) \\
\hline GDP CN & $1,488,136$ & $1,552,975$ \\
\hline Total GDP in Germany & $2,163,794$ & $2,322,210$ \\
\hline \% CN over the total & $68.77 \%$ & $66.87 \%$ \\
\hline
\end{tabular}

Table 4. Commuting vs employment for CN (2003 and 2007)

\begin{tabular}{cccc}
\hline Year & CN Commuters & Total CN Employment & CN Commuters/Total CN Employment \\
\hline 2003 & $4,408,220$ & $16,629,621$ & $26.5 \%$ \\
\hline 2007 & $4,464,101$ & $15,980,673$ & $27.9 \%$ \\
\hline
\end{tabular}

After these introductory statistics, highlighting the role of the $\mathrm{CN}$ in the whole of Germany in terms of GDP, employment and commuting, we now analyse the spatial arrangement of employment opportunities in the German CN. As previously anticipated in Section 1 and Section 2, our ultimate aim is the exploration of the relevance of space between work and workers in a highly connected system such as the German CN. In this context, we will use the accessibility indicator (instead of proximity), as a suitable instrument to measure the intensity/ propensity of knowledge flows, which are related to the mobility and interaction of workers in the CN (see Section 2).

As a first empirical step, in order to estimate - in our future research - the effects of improved transport infrastructure and/or changed localization patterns, it is essential to measure the 'behavioural' patterns of the $\mathrm{CN}$ workers, at least at an aggregate level. This investigation will be performed by means of a spatial interaction model, where the deterrence function is supposed to be 
either of the exponential type (exploring homogeneous connectivity patterns) or of the power type (exploring heterogeneous connectivity patterns). Next, the emerging sensitivity parameters will be introduced in the related accessibility functions. These accessibility indicators will be finally compared with labour market size indicators, in order to examine the efficiency of the spatial organization of jobs in the $\mathrm{CN}$.

The results of the above empirical steps will be shown and discussed in Section 4.

\section{Empirical Analysis: The Spatial Organization of Labour Markets in the German City Network}

\subsection{A Spatial Interaction Model for the City Network}

In the last century, spatial interaction analysis has been the central focus of several theories and models, aiming to map out and predict spatial flow patterns emerging as a outcome from given spatial configurations (Reggiani and Bucci, 2008). In this framework, a spatial interaction model (SIM) - given its analytical compatibility withy micro-economic and statistical information/entropy theory - can be conceived of as the 'universal' model, able to capture the essence of spatial phenomena (such as commuting, migration, telephone and email interaction, etc.), where physical and virtual interaction/connectivity plays a fundamental role. A relevant component in a SIM is the utility/deterrence function, which embeds the behavioural (aggregate) propensity to interact (by means of the time /cost sensitivity parameters), as well as the connectivity spatial pattern (by means of the commuting travel times/costs).

The first step of our empirical application aimed to identify - by means of SIMs - the CN spatial (aggregate) pattern dynamics, In particular, as a first exploratory analysis, an unconstrained SIM was utilized in order to extrapolate the time sensitivity parameters for the two years under analysis (2003 and 2007), as well as for different deterrence functions (exponential and power) and different intra-zonal travel times (10 and 20 minutes). These sensitivity parameters were then introduced in the formulation and calculation of the accessibility functions (Section 4.2).

We then adopted an unconstrained SIM of the following type:

$$
T_{i j}=K O_{i} D_{j} f\left(t_{i j}\right) .
$$

In Equation (2), the flows $T_{i j}$ represent the commuting flows (employees) from the origin (district) $i$ to the destination (district) $j$. They are a function of the outflows $O_{i}$ and of the inflows $D_{j}$, as well as of the deterrence function $f\left(t_{i j}\right) ; t_{i j}$ is the travel time between $i$ and $j$; and the parameter $K$ 
is a scaling factor. Concerning the form of $f\left(t_{i j}\right)$, two different functional specifications are here taken into account, in order to test the homogeneous/heterogeneous connectivity patterns ${ }^{6}$ :

1) the exponential-decay function:

$$
f\left(t_{i j}\right)=e^{-\beta_{1} t_{i j}},
$$

2) the power-decay function:

$$
f\left(t_{i j}\right)=t_{i j}^{-\gamma}
$$

Table 5 presents the calibration the $\mathrm{CN}$ unconstrained SIM. In particular, we consider as zone of origin $i$ and destination $j$ each of the $17 \mathrm{CN}^{\text {districts }}{ }^{7}$ (Kreise) in Germany, including of their catchment areas. The data utilized for the calibration concern the numbers of employees residing in district $i$ and working in district $j$, that is, home-to-work trips between the $17 \mathrm{CN}$ districts (conceived of as centroids of their related catchment areas). The years under analysis are 2003 and 2007.

Concerning the $\mathrm{CN} 17 \times 17$ travel time matrix (in minutes), we derived this new matrix from the original travel time matrix 439 x 439 (weighted sum of 75 per cent by road and 25 per cent by train, according to a German mobility survey about choice of transport by Zumkeller et al. (2007). Here, we considered two different cases for the intra-zonal travel time (i.e. for the diagonal of the matrix): 10 and 20 minutes. Then, the $\mathrm{CN}$ catchment area-travel time matrix (17x17) was generated as the mean travel time weighted by commuters referring either to the 214 districts or to the 204 districts (see Footnote Error! Bookmark not defined.).

Table 5 displays the following results:

i. In both years (2003 and 2007), the power deterrence function fits better, by indicating a tendency for part of the mobility to be for longer trips (tail). This result is consistent with the findings of previous research based on the whole system, i.e. on the 439 German districts (see Reggiani and Bucci, 2008, and Annex A). In addition, variations (slight decreases) of the time sensitivity parameter $\gamma_{1}, \gamma_{2}, \gamma_{3}$ and $\gamma_{4}$ are shown:

- $\quad$ in 2007 compared with $2003\left(\gamma_{1}\right.$ vs. $\gamma_{2} ; \gamma_{3}$ vs. $\left.\gamma_{4}\right)$;

- when intra-zonal travel time is shorter $\left(\gamma_{1}\right.$ vs. $\gamma_{3} ; \gamma_{2}$ vs. $\left.\gamma_{4}\right)$.

\footnotetext{
${ }^{6}$ Other types of deterrence functions could have been used as well (for a review, see Reggiani and Bucci, 2008). We have chosen the exponential and power forms for their capability to embed homogenous vs heterogeneous patterns, according also to Fotheringham and O'Kelly (1989), Richardson (1969), and Willigers (2007).

${ }^{7}$ The data are aggregated at the NUTS III level (i.e. the German administrative districts, called Kreise) of the EU, and were collected by the Federal Employment Services (Bundesagentur für Arbeit, BA) for social security purposes (IAB, Nuremberg, Germany).
} 
ii. The exponential function fits less well, a finding also obtained in previous research (Reggiani and Bucci, 2008). Here, behavioural aggregate patterns (i.e. the time sensitivity parameters $\beta_{1}, \beta_{2}, \beta_{3}$ and $\beta_{4}$ ) are stable over the years 2003-2007 and over different intrazonal travel times.

Table 5. Calibration results for the unconstrained SIM concerning the CN (2003 and 2007)

\begin{tabular}{lrc|rc}
\hline \multirow{2}{*}{ Deterrence Function } & \multicolumn{2}{c|}{2003} & \multicolumn{2}{c}{2007} \\
\cline { 2 - 5 } & $R^{2}$ & Parameter & $R^{2}$ & Parameter \\
Exponential (10 min.) & 0.486 & $\beta_{1}=-0.011$ & 0.522 & $\beta_{2}=-0.011$ \\
Exponential (20 min.) & 0.477 & $\beta_{3}=-0.011$ & 0.513 & $\beta_{4}=-0.011$ \\
& & & & \\
Power (10 min.) & 0.782 & $\gamma_{1}=-1.928$ & 0.810 & $\gamma_{2}=-1.919$ \\
Power (20 min.) & 0.749 & $\gamma_{3}=-2.037$ & 0.779 & $\gamma_{4}=-2.023$ \\
\hline
\end{tabular}

All in all, the previous findings, highlighting the very good fit of the power deterrence function for both years (2003 and 2007), support the presence of heterogeneous patterns in the spatial commuting $\mathrm{CN}$. This result reinforces previous analyses concerning the heterogeneity of the commuting flows in the whole of Germany for the same years (Patuelli, 2007).

\subsection{Job Accessibility for the City Network}

After having explored the spatial commuting patterns of the $\mathrm{CN}$, the next step in our analysis was to investigate the dynamics of the accessibility indicators and their relation with the labour market size (for each $\mathrm{CN}$ district). The relevance of the accessibility as an instrument to "make the role of mobility and interaction patterns in knowledge production functions operational" (Karlsson et al., 2006, p.3) has been emphasized by several contributions (for a review, see Östh, 2007).

The relationship between accessibility and labour markets is an important one, because it bears on the efficiency of the labour market: if relatively many jobs are concentrated in less accessible regions (as suggested by the different rankings in the accessibility and $D_{j}$ ), then total commuting costs could be reduced by increasing accessibility in high density areas or by shifting jobs to high accessibility nodes.

In our empirical analysis, we utilized the potential measure of accessibility (1), as defined in Section 2, which is well-known in the scientific literature for its rich theoretical foundations and 'universal' properties (Reggiani, 1998). Detailed discussion on accessibility measures can be found in, amongst others, Geurs and van Wee (2004) and Östh (2007). Equation (1) takes into account the relevant effects of the spatial configuration of destinations, in particular it can capture how a destination is located relative to alternative opportunities. In particular, when agglomeration or 
competition effects are present, the distribution of trips - and the related accessibility function will be affected by the clustering systems of destinations, in addition to the cost/travel time (Fotheringham, 1984; McArthur, 2010). The functional form in (1) should then capture these spatial structure effects.

Consequently, analogously to the two SIM formulations (Section 4.1), we constructed and analysed two specifications of the potential accessibility (1), by introducing the two different deterrence forms (3) and (4), viz. the exponential and the power function, in order to take into account homogenous vs. heterogeneous spatial connectivity patterns. The two adopted accessibility indicators read as follows:

$$
\begin{aligned}
& A_{i} \text { exponential }=\sum_{j} D_{j}\left(e^{-\beta t_{i j}}\right) \\
& A_{i} \text { power }=\sum_{j} D_{j}\left(t_{i j}^{-\gamma}\right)
\end{aligned}
$$

where the variable $D_{j}$ represents the number of workplaces in district $j$; and $t_{i j}$ represents the commuting travel time from district $i$ to $j$. The values of the coefficients $\beta$ and $\gamma$ (time sensitivity parameters), implemented in Equations (5) and (6), were those emerging from the SIM calibration and displayed in Table 5.

The two accessibility expressions (5) and (6) were calculated for the two years under analysis (2003 and 2007), as well as for different intra-zonal travel time (10 and 20 minutes). The accessibility results are displayed in Table 6, according to an ordinal ranking.

The hierarchical accessibility order - in Table 6 - shows an overall stability over the years, as well as between the power and the exponential accessibility (the related correlation analysis is displayed in Annex B). The results emerging from different intra-zonal travel times - in the different accessibility measures - also suggest a rather stable/robust pattern, although some exception (in terms of ranking) can be noticed for the power accessibility measure of those districts with a very high intra-zonal flow. A clear example is Berlin which has a very high intra-zonal flow: the shorter the intra-zonal travel time, the higher the accessibility is. A second example is Stuttgart that improves its ranking in accessibility when accessibility is derived from an impedence function with a power-law functional form.

All in all, concerning the $\mathrm{CN}$ accessibility results, the districts of Dortmund, Düsseldorf, Essen, Frankfurt, Cologne, and Stuttgart are placed in the first six positions, thus showing the dominance of the West Germany/Ruhr-Rhine area in job accessibility. The centrality in accessibility of these six districts is also visible by observing the reduced role of the different impedance functions vs. the 
labour market size (see Tables 6 and 7). We can then conjecture an efficient infrastructure spatial network associated to these six $\mathrm{CN}$ labour market areas.

The final step of our analysis was then the investigation of the labour markets 'strength' in the $\mathrm{CN}$ districts, in order to examine its relationship with the accessibility patterns. We considered the number of employees as an indicator of the labour market districts strength.

Table 7 displays the ranking of the employees for the 17 selected districts (including the employees of the related catchment areas), for the years 2003 and 2007. Here we can see that, in general, the hierarchical dynamics of $D_{j}$ (employees) matches the dynamic hierarchical order of the accessibility, apart from a few specific cases.

In particular, the six districts of the West Germany/Ruhr-Rhine area and the Main-RhineNeckar area, i.e. Frankfurt, Stuttgart, Düsseldorf, Cologne, Dortmund, Essen, remain - in both years - in the first top nine positions, thus showing a good consistency between workplaces and accessibility over the years. On the other hand, the districts of Munich and Hamburg show a difference - in both years - between the two rankings, i.e. a high number of employees, but lower accessibility. The difference between the two rankings hinges on the deterrence/cost function, which accounts for the costs imposed on commuters to travel to their workplaces. The higher the accessibility of an area the less burdensome is commuting. However, our hypothesis of identifying the catchment area as that within 60 minutes of the district, may have caused some underestimation in the accessibility levels of these two particular districts (Munich and Hamburg), which do not appear to operate efficiently in their spatial organization of jobs.

It is not surprising to observe that the employment hierarchy of the districts matches the related GDP ranking over the years (Tables C1 and C2 in Annex C) extremely well, in fact, the correlation between the accessibility and the GDP ranking for 2003 and 2007 is -0.97 and -0.96 , respectively. In summary, from all these results, we can argue that the hierarchical analysis of $\mathrm{CN}$ accessibility vs. the hierarchic CN employment and/or GDP might be used as an instrument able to suggest the (beneficial) effects of the spatial organization of $\mathrm{CN}$ labour market flows. 
Table 6. Accessibility ranking of the $17 \mathrm{CN}$ districts, for two different deterrence functions (exponential and power), and two different intra-zonal travel times (10 and $20 \mathrm{~min}$ ); in 2003 and 2007; ordinal order: $1=$ most accessible; $17=$ least accessible.

\begin{tabular}{|l|c|c|c|c|c|c|c|c|}
\hline \multirow{2}{*}{\multicolumn{1}{|c|}{ CN Districts }} & \multicolumn{4}{|c|}{$\mathbf{2 0 0 3}$} & \multicolumn{4}{c|}{2007} \\
\cline { 2 - 10 } & Exp10 & Exp20 & Pow10 & Pow20 & Exp10 & Exp20 & Pow10 & Pow20 \\
\hline 02000 Hamburg, Freie und Hansestadt & 13 & 13 & 13 & 14 & 14 & 14 & 12 & 14 \\
\hline 03241 Region Hannover & 8 & 8 & 8 & 8 & 10 & 10 & 11 & 12 \\
\hline 04011 Bremen, Stadt & 11 & 11 & 15 & 15 & 12 & 12 & 15 & 15 \\
\hline 05111 Düsseldorf, Stadt & 2 & 2 & 5 & 1 & 2 & 2 & 3 & 1 \\
\hline 05113 Essen, Stadt & 3 & 3 & 1 & 3 & 4 & 3 & 2 & 2 \\
\hline 05314 Bonn, Stadt & 7 & 7 & 14 & 11 & 7 & 7 & 13 & 10 \\
\hline 05315 Cologne, Stadt & 4 & 4 & 7 & 5 & 5 & 6 & 6 & 5 \\
\hline 05913 Dortmund, Stadt & 1 & 1 & 2 & 4 & 1 & 1 & 1 & 4 \\
\hline 06412 Frankfurt am Main, Stadt & 5 & 5 & 3 & 2 & 3 & 5 & 4 & 3 \\
\hline 08111 Stuttgart, Landeshauptstadt & 10 & 10 & 6 & 7 & 9 & 9 & 5 & 7 \\
\hline 08212 Karlsruhe, Stadt & 9 & 9 & 10 & 9 & 8 & 8 & 9 & 8 \\
\hline 08222 Mannheim, Universiätsstadt & 6 & 6 & 9 & 6 & 6 & 4 & 8 & 6 \\
\hline 09162 Munich, Landeshauptstadt & 14 & 14 & 11 & 10 & 13 & 13 & 10 & 9 \\
\hline 09564 Nuremberg, Stadt & 12 & 12 & 12 & 13 & 11 & 11 & 14 & 13 \\
\hline 11000 Berlin, Stadt & 16 & 16 & 4 & 12 & 15 & 16 & 7 & 11 \\
\hline 14262 Dresden, Stadt & 17 & 17 & 17 & 17 & 17 & 17 & 17 & 17 \\
\hline 14365 Leipzig, Stadt & 15 & 15 & 16 & 16 & 16 & 15 & 16 & 16 \\
\hline
\end{tabular}

Note $_{1}$ : The abbreviations Exp and Pow used in Table 5 indicate, respectively, the exponential and the power function. Note $_{2}$ : The numbers 10 and 20 in the column headings indicates the minutes used as intra-zonal travel time in the original data.

Table 7. Labour market size for each CN district (cardinal order; 2003 and 2007)

\begin{tabular}{lclr}
\hline \multicolumn{1}{c}{ CN Districts } & $\boldsymbol{D}_{\boldsymbol{j}}(\mathbf{2 0 0 3})$ & \multicolumn{1}{c}{ CN Districts } & $\boldsymbol{D}_{\boldsymbol{j}}(\mathbf{2 0 0 7})$ \\
\hline 06412 Frankfurt am Main, Stadt & $1,664,580$ & 06412 Frankfurt am Main, Stadt & $1,640,817$ \\
09162 Munich, Landeshauptstadt & $1,512,569$ & 09162 Munich, Landeshauptstadt & $1,502,528$ \\
03241 Region Hannover & $1,420,333$ & 08111 Stuttgart, Landeshauptstadt & $1,295,823$ \\
08111 Stuttgart, Landeshauptstadt & $1,319,851$ & 02000 Hamburg, Freie und Hansestadt & $1,120,914$ \\
02000 Hamburg, Freie und Hansestadt & $1,175,352$ & 05111 Düsseldorf, Stadt & $1,046,512$ \\
05111 Düsseldorf, Stadt & $1,065,931$ & 11000 Berlin, Stadt & $1,036,321$ \\
05315 Cologne, Stadt & $1,040,333$ & 05315 Cologne, Stadt & $1,016,720$ \\
05913 Dortmund, Stadt & $1,032,616$ & 05913 Dortmund, Stadt & $1,009,257$ \\
05113 Essen, Stadt & $1,031,656$ & 05113 Essen, Stadt & $1,008,983$ \\
11000 Berlin, Stadt & $1,011,235$ & 03241 Region Hannover & 912,952 \\
09564 Nuremberg, Stadt & 834,605 & 09564 Nuremberg, Stadt & 823,953 \\
08222 Mannheim, Universitätsstadt & 764,481 & 08222 Mannheim, Universitätsstadt & 761,614 \\
08212 Karlsruhe, Stadt & 650,356 & 08212 Karlsruhe, Stadt & 665,949 \\
04011 Bremen, Stadt & 585,145 & 04011 Bremen, Stadt & 633,144 \\
14365 Leipzig, Stadt & 567,801 & 14365 Leipzig, Stadt & 558,334 \\
14262 Dresden, Stadt & 482,103 & 14262 Dresden, Stadt & 476,774 \\
05314 Bonn, Stadt & 470,674 & 05314 Bonn, Stadt & 470,078 \\
\hline
\end{tabular}

Note: The labour market size is measured by its $D j$ 's value (i.e. the number of workplaces) for each district. 


\section{5 . Conclusions}

The objective of this paper was to employ notions from complex network theory to German commuting flows. First, we aimed to explore the City Network $(\mathrm{CN})$ concept and its capability to efficiently summarize the complex dynamics that characterize the German economy. This is an important issue, because, to the extent that this is happening, one may hypothesize that the $\mathrm{CN}$ could be the main thrust of economic progress for the whole country. This is a hypothesis that has found some initial support in this paper and that warrants more in-depth analysis. Second, since recent studies have found accessibility to have a positive effect on economic growth (e.g. Karlsson et al., 2006), we have complemented these studies by linking accessibility and the geographical location of jobs to the efficient operation of local labour markets. And, thirdly, we investigated spatial accessibility patterns in the main $\mathrm{CN}$ in Germany by considering different deterrence functions. In particular, the link between the accessibility concept and the $\mathrm{CN}$ concept might be interesting, because it gives insights into the distribution of economic activities and the related (dis)equilibrium of the regional development pattern.

Our empirical analyses confirm a very good fit of the power deterrence function for both years (2003 and 2007), which supports the presence of heterogeneous patterns in the spatial commuting $\mathrm{CN}$. This result reinforces previous analyses concerning the heterogeneity of the commuting flows in the whole of Germany for the same years. There might be a slight decrease in time sensitivity which could be interpreted that people are willing to spend more commuting time as a result of the tight labour market caused by the unemployment shock in 2005/2006.

Finally, concerning the spatial organization of the labour market flows, we find a dominance of the West Germany/Ruhr-Rhine area, in particular the districts of Dortmund, Düsseldorf, Essen, Frankfurt, Cologne and Stuttgart. In general, the ranking of employees per district matches the hierarchical order of the accessibility, apart from Munich and Hamburg. In these two cities, it seems that commuting is relatively burdensome due to the geographical position of the related labour markets. However, the high wage level and a wide range of job offers in Munich and Hamburg attracts a higher than average number of commuters. All in all, especially the labour markets that are emerging in the western German districts can be considered as a rather efficient operating subnetwork from the viewpoint of the spatial distribution of workplaces.

Further research should highlight the relevance of pecuniary commuting costs, also including the opportunity costs that emerge by considering congestion variables. Another relevant aspect would be to disaggregate data allowing diverse effects for different socio-economic subgroups (gender, qualification, age). Sensitivity analysis for different time thresholds could clarify the role of catchment areas. 


\section{Acknowledgment}

The authors wish to thank Uwe Blien (IAB, Nuremberg, Germany) for kindly providing the data set and valuable comments. In addition, they would like to thank two anonymous referees for the interesting suggestions.

\section{References}

Bode, E., 2006. Commuting, Externalities and the Geographical Sizes of Metropolitan Areas. Kiel Working Paper no. 1289, Kiel Institute for the World Economy, Kiel.

Dosi, G., 1998. The Nature of Innovative Process. In: Dosi, G., Freeman, C., Nelson, R., Silverberg, G., Soete, L., (Eds), Technical Change and Economic Theory. Pinter: London, pp. 221-238.

Duranton, G., 2000, Urbanization, Urban Structure and Growth. In: Huriot, J.-M., Thisse, J. F. (Eds), Economics of Cities: Theoretical Perspectives. Cambridge University Press: Cambridge, pp. 290-317.

Davis, D., Weinstein, D., 1999. Economic Geography and Regional Production Structure. European Economic Review 43(2), 397-407.

Eckey, H.-F., Kosfeld, R., Türck, M., 2006. Abgrenzung deutscher Arbeitsmarktregionen. Raumforschung und Raumordnung 64(4), 299-309.

Fotheringham, A. S., 1984. Spatial Flows and Spatial Patterns. Environment and Planning 16 (4), 529543.

Fujita, M., Thisse, J.-F., 2002. The Economics of Agglomeration. Cambridge University Press: Cambridge.

Fujita, M., Krugman, P., Venables, A.J., 1999. The Spatial Economic. MIT Press: Cambridge.

Geurs, K. T., Wee, B. van, 2004. Accessibility Evaluation of Land-Use and Transport Strategies Review and Research Directions. Journal of Transport Geography 12, 127-140.

Glaeser, E. L., 1998. Are Cities Dying?. Journal of Economic Perspectives 12(2), 139-160.

Glaeser, E. L., Laibson, D., Sacerdote, B., 2000. The Economic Approach to Social Capital. NBER Working Paper 7728, National Bureau of Economic Research, Washington DC.

Glaeser, E.L., Kallal H. D., Scheinkman J. A., Shleifer, A., 1992. Growth in Cities, Journal of Political Economy 100(6), 1126-52.

Granato, N., Haas, A., Hamann, S., Niebuhr A., 2009. Arbeitskräftemobilität in Deutschland Qualifikationsspezifische Befunde Regionaler Wanderungs- und Pendlerströme. Raumforschung und Raumordnung 67(1), 21-33. 
Hägerstrand, T., 1953. Innovationsförloppet ur korologisk synpunkt. Lunds Universitets Geografiska Institution, PHD 304, Lunds Universitet, Lund. Translated in 1967 as: Innovation Diffusion as a Spatial Process. University of Chicago Press: Chicago.

Henderson, J.V., Kincoro, A., Turner, M., 1995. Industrial Development in Cities. Journal of Political Economy, 103(5), 1067-1085.

Karlsson, C., Gråsjö, U., Andersson, M., 2006. Regional Knowledge Accessibility and Regional Economic Growth. Paper presented at the $46^{\text {th }}$ Conference of the European Regional Science Association, Volos (Greece), 30 August - 3 September.

Krugman, P., 1996. Urban Concentration: The Role of Increasing Returns and Transport Costs. International Regional Science Review 19(1\&2), 5-30.

McArthur, D. P., 2010. Regional Labour Markets and Spatial Interaction Mechanisms. PH.D. Thesis, NHH (Norwegian School of Economics and Business Administration), Bergen.

Niebuhr, A., Granato, N., Haas, A., Hamann S., 2009. Does Labour Mobility Reduce Disparities between Regional Labour Markets in Germany? IAB Discussion Paper, 15/2009, Nürnberg.

Nijkamp, P., 2008. XXQ Factors for Sustainable Urban Development: A Systems Economics View. Romanian Journal of Regional Science 2(1), 1-33.

Nijkamp, P., 2009. Regional Development as Self-Organized Converging Growth. In: KochendörferLucius, G., and Pleskovic, B., (Eds), Spatial Disparities and Development. The World Bank: Washington DC, pp. 265-281.

Oort, F. Van, McCann, P., 2009. Economic Growth in Cities and Urban Networks. In: KochendörferLucius, G., and Pleskovic, B., (Eds), Spatial Disparities and Development, The World Bank, Washington DC, pp. 91-108.

Östh, J., 2007. Home, Job and Space. Mapping and Modeling the Labor Market. Geografiska Regionstudier, 72, Uppsala University, Uppsala.

Patuelli, R., 2007. Regional Labour Markets in Germany: Statistical Analysis of Spatio-Temporal Disparities and Network Structures. Unpublished Ph.D. Thesis, VU University Amsterdam, Amsterdam.

Polèse, M., 2005, Cities and National Economic Growth: A Reappraisal. Urban Studies 42(8), 14291451.

Pompili, T., 2006. Networks within Cities and among Cities. Paper presented at the $46^{\text {th }}$ Conference of the European Regional Science Association, Volos (Greece), 30 August - 3 September.

Quigley, J.M., 1998. Urban Diversity and Economic Growth. Journal of Economic Perspectives 12, 127-138.

Reggiani, A., (Eds), 1998. Accessibility, Trade and Locational Behaviour. Ashgate: Aldershot, UK. 
Reggiani, A., Bucci, P., 2008. Accessibility and Impedance Forms: Empirical Applications to the German Commuting Network. Paper presented at NARSC Conference, N.Y, $19-22$ November 2008.

Reggiani, A., Nijkamp, P., (Eds.), 2006. Spatial Dynamics, Networks and Modelling. Edward Elgar: Cheltenham, UK.

Reggiani, A., Nijkamp, P., (Eds.), 2009. Complexity and Spatial Networks. Springer-Verlag: Berlin.

Richardson, H.W., 1969. Elements of Regional Economics. Penguin Books: Harmondsworth.

Russo, G., Reggiani A., Nijkamp P., 2007. Spatial Activity and Labour Market Patterns: A Connectivity Analysis of Commuting Flows in Germany. The Annals of Regional Science 41, 789-811.

Simon, H. A., 1962. The Architecture of Complexity. Proceeding of the American Philosophical Society 106(6), 467-482.

Uhlig, H., 2006. Regional Labor Markets, Network Externalities and Migration: The Case of German Reunification. The American Economic Review 96(2), 383-387.

Weibull J. W., 1980. On the Numerical Measurement of Accessibility. Environment and Planning A 12(1), 53-67.

Willigers J., Floor, H., Wee B. van, 2007. Accessibility Indicators for Location Choices of Offices: an Application to the Intraregional Distributive Effects of High-Speed Rail in the Netherlands. Environment and Planning A, 39, pp. 2086-2098.

Zumkeller, D., Chlond, B., Lipps O., 2007. Deutsches Mobilitätspanel (MOP)-wissenschaftliche Begleitung und erste Auswertungen. Zwischenbericht, Institut für Verkehrswesen, Karlsruhe. 


\section{Annex A . Calibration Results of SIM}

Table A1 and Table A2 illustrate the calibration results of the SIM, by considering the network of all the German districts (349) (Reggiani and Bucci, 2008).

Table A1. Estimation results concerning SIM (a) associated with the two deterrence functions (3) and (4): 349 districts; year 2003

\begin{tabular}{lll}
\hline Deterrence Function & $R^{2}$ & Parameter \\
Exponential & 0.339 & $\beta^{\prime}=-0.009$ \\
Power & 0.574 & $\gamma^{\prime}=-1.882$ \\
\hline
\end{tabular}

Table A2. Estimation results concerning SIM (a) associated with the two deterrence functions (3) and (4): 349 districts; year 2007

\begin{tabular}{lll}
\hline Deterrence Function & $R^{2}$ & Parameter \\
Exponential & 0.334 & $\beta^{\prime}=-0.008$ \\
Power & 0.566 & $\gamma^{\prime}=-1.835$ \\
\hline
\end{tabular}




\section{Annex B . Correlation Results}

Table B1 below shows the degree of correlation between the different accessibility rankings (emerging from the accessibility formulation embedding the exponential and power function) concerning: a) each year (2003 and 2007); b) each different intra-zonal travel times (10 and 20 minutes). For example, the linear correlation between the ranking obtained using the 2003 city network and that obtained using a power form and intra-zonal commuting time of 10 minutes (2003_power10) and the ranking obtained using the 2007 city network and that obtained using a power form and inter-zonal commuting of 10 minutes (2007_power10), is as high as 0.846.

Table B1. Robustness analysis: pairwise linear correlation between the ranking obtained under different conditions: year, deterrence function and intra-zonal time $(\mathrm{N}=17)$

\begin{tabular}{|c|c|c|c|c|c|c|c|c|}
\hline Pearson Correlation & 2003_Power10 & 2003_Power20 & 2003_Exp10 & 2003_Exp20 & 2007_Power10 & 2007_Power20 & 2007_Exp10 & 2007_Exp20 \\
\hline 2003_Power10 & 1 & $.858^{* *}$ & $.667 * *$ & $.667 * *$ & $.956^{* *}$ & $.846^{* *}$ & $.713 * *$ & $.669 * *$ \\
\hline 2003_Power20 & $.858 * *$ & 1 & $.882 * *$ & $.882 * *$ & $.914 * *$ & $.973 * *$ & $.917 * *$ & $.892 * *$ \\
\hline 2003_Exp10 & $.667 * *$ & $.882 * *$ & 1 & $1.000 * *$ & $.755^{* *}$ & $.853 * *$ & $.978 * *$ & $.978 * *$ \\
\hline 2003_Exp20 & $.667 * *$ & $.882 * *$ & $1.000 * *$ & 1 & $.755^{* *}$ & $.853 * *$ & $.978 * *$ & $.978 * *$ \\
\hline 2007_Power10 & $.956^{* *}$ & $.914^{* *}$ & $.755 * *$ & $.755^{* *}$ & 1 & $.931 * *$ & $.804 * *$ & $.772 * *$ \\
\hline 2007_Power20 & $.846 * *$ & $.973 * *$ & $.853 * *$ & $.853 * *$ & $.931 * *$ & 1 & $.907 * *$ & $.887 * *$ \\
\hline 2007_Exp10 & $.713 * *$ & $.917 * *$ & $.978 * *$ & $.978 * *$ & $.804 * *$ & $.907 * *$ & 1 & $.985 * *$ \\
\hline 2007_Exp20 & $.669 * *$ & $.892 * *$ & $.978 * *$ & $.978 * *$ & $.772 * *$ & $.887 * *$ & $.985 * *$ & 1 \\
\hline
\end{tabular}

** Correlation is significant at the 0.01 level (2-tailed)

* Correlation is significant at the 0.05 level (2-tailed).

Notes: 2003_Power10 means the accessibility measure - embedding a power form with intra-zonal time of 10 minutes - calculated for the year 2003 . 


\section{Annex C. GDP Rankings}

Tables C1 and C2 display, respectively, the GDP ranking of the CN districts, for 2003 and 2007.

Table C1. GDP (in mln euros) for each of the CN district, including its catchment area, for 2003

\begin{tabular}{lcc}
\hline \multicolumn{1}{c}{ CN Districts } & $\mathbf{2 0 0 3}$ & $\begin{array}{c}\text { Number of Districts in the } \\
\text { Catchment Area }\end{array}$ \\
\hline 09162 Munich, Landeshauptstadt & 165,442 & 22 \\
06412 Frankfurt am Main, Stadt & 164,986 & 19 \\
02000 Hamburg, Freie und Hansestadt & 122,847 & 11 \\
08111 Stuttgart, Landeshauptstadt & 120,135 & 11 \\
03241 Region Hannover & 117,241 & 21 \\
05111 Düsseldorf, Stadt & 98,026 & 9 \\
05315 Cologne, Stadt & 91,353 & 9 \\
05913 Dortmund, Stadt & 88,393 & 11 \\
05113 Essen, Stadt & 88,043 & 10 \\
11000 Berlin, Stadt & 85,634 & 3 \\
09564 Nuremberg, Stadt & 73,141 & 21 \\
08222 Mannheim, Universitätsstadt & 68,763 & 16 \\
08212 Karlsruhe, Stadt & 57,245 & 10 \\
04011 Bremen, Stadt & 50,915 & 12 \\
05314 Bonn, Stadt & 42,401 & 7 \\
14262 Dresden, Stadt & 32,009 & 9 \\
14365 Leipzig, Stadt & 21,562 & 13 \\
\hline
\end{tabular}

Table C2. GDP (in mln euros) for each of the CN district, including its catchment area, for 2007

\begin{tabular}{lcc}
\hline \multicolumn{1}{c}{ CN Districts } & $\mathbf{2 0 0 7}$ & $\begin{array}{c}\text { Number of Districts in the } \\
\text { Catchment Area }\end{array}$ \\
\hline 09162 Munich, Landeshauptstadt & 178,896 & 21 \\
06412 Frankfurt am Main, Stadt & 175,488 & 19 \\
02000 Hamburg, Freie und Hansestadt & 128,261 & 10 \\
08111 Stuttgart, Landeshauptstadt & 126,153 & 11 \\
05111 Düsseldorf, Stadt & 104,403 & 9 \\
05315 Cologne, Stadt & 97,244 & 9 \\
05913 Dortmund, Stadt & 97,057 & 11 \\
05113 Essen, Stadt & 94,129 & 10 \\
11000 Berlin, Stadt & 91,961 & 4 \\
03241 Region Hannover & 85,822 & 12 \\
09564 Nuremberg, Stadt & 75,916 & 20 \\
08222 Mannheim, Universitätsstadt & 72,731 & 16 \\
08212 Karlsruhe, Stadt & 62,418 & 10 \\
04011 Bremen, Stadt & 60,021 & 7 \\
05314 Bonn, Stadt & 45,019 & 9 \\
14262 Dresden, Stadt & 34,225 & 13 \\
14365 Leipzig, Stadt & 23,231 & \\
\hline
\end{tabular}

